\title{
PENDAPATAN NELAYAN TRADISIONAL DI KECAMATAN LANGSA BARO KOTA LANGSA
}

\author{
Rozalina ${ }^{1}$, Reynita Pertiwi ${ }^{2}$ \\ ${ }^{1}$ Dosen Fakultas Pertanian Universitas Samudra \\ ${ }^{2}$ Mahasiswa Program Studi Agribisnis Fakultas Pertanian Universitas Samudra
}

\begin{abstract}
Ringkasan
Penelitian ini menggunakan metode survei. Lokasi penelitian dilakukan di kecamatan Langsa Baro. Penentuan desa sampel dilakukan secara purposive (sengaja). Pengambilan nelayan sampel dilakukan secara simple random sampling (acak sederhana). Jumlah nelayan sampel sebanyak 29 orang terdiri dari 18 orang di Desa Alue Dua, 10 orang di Desa Birem Puntong , 1 orang di Desa Timbang langsa.Objek penelitian adalah nelayan tradisional yang menggunakan sampan atau perahu yag menggunakan mesin sampan atau perahu dengan mesin motor tempel dan menggunakan alat tangkap yang sederhana seperti pancing dan jala/jaring, Ruang lingkup penelitian adalah pendapatan nelayan tradisional yang ada di Kecamatan Langsa Baro. Penelitian ini dilaksanakan pada bulan November sampai Desember 2017. Hasil Penelitian diperoleh rata-rata pendapatan bersih nelayan sampel di kecamatan Langsa Baro yaitu sebesar Rp.862.084/Bulan.Rata-rata pendapatan bersih tertinggi berada di Desa Timbang Langsa yaitu sebesar Rp.1.101.861/Bulan.Sedangkan pendapatan bersih terkecil berada di Desa Birem Puntong sebesar Rp.703.617/Bulan. Pendapatan bersih nelayan tradisional masih berada dalam kategori yang sangat rendah karena jika dibandingkan dengan tingkat pendapatan sesuai UMP (Upah Minimum Provinsi) Rp.2.800.000/Bln, hal ini yang menyebabkan para nelayan tradisional tidak sejahtera atau miskin. Selain itu tingkat pendapatan yang rendah juga dikarenakan pembayaran upah tenaga kerja.
\end{abstract}

Kata kunci : Pendapatan, Nelayan Tradisional

\section{Pendahuluan}

Nelayan adalah seseorang yang hidup dari mata pencaharian hasil laut.Di Indonesia para nelayan biasanya bermukim di daerah pinggir pantai atau pesisir laut.Untuk mewujudkan masyarakat yang sejahtera dalam arti sebenarnya adalah tujuan mulia yang hendak dicapai oleh bangsa Indonesia.Dalam peningkatan kesejahteraan penduduk dapat dilakukan apabila pendapatan penduduk mengalami peningkatan yang cukup hingga mampu memenuhi kebutuhan dasar untuk kehidupannya.

Dilihat dari teknologi peralatan tangkap yang digunakan dapat dibedakan dalam dua kategori, yaitu usaha nelayan modern dan usaha nelayan tradisional.Usaha nelayan modern menggunakan teknologi penangkapan yang lebih canggih dibandingkan dengan usaha nelayan tradisional. Ukuran modernitas bukan semata-mata karena pengunaan mesin motor untuk menggerakkan perahu, melainkan juga besar kecilnya motor yang digunakan serta tingkat eksploitasi dari alat tangkap yang digunakan. Perbedaan modernitas teknologi alat tangkap juga akan berpengaruh pada kemampuan jelajah operasional mereka.

Kota Langsa merupakan Kota pesisir yang memiliki garis pantai sepanjang 16 $\mathrm{km}$. Secara geografis kecamatan Langsa Baro terletak pada $4^{0} 27^{\prime}-1.56^{\prime}$ LU dan $\begin{array}{llllll}97^{0} & 56^{\prime} & - & 10 & 97^{\prime} & \text { BT. }\end{array}$ KecamatanLangsa Baro menempati areal seluas $40,10 \mathrm{~km}^{2}$ yang terdiri dari 12 desa/gampong yang sebagian besar penduduknya berprofesi sebagai nelayan 
tradisional yang menangkap hasil lautnya menggunakan perahu kecil/sampan. Tingkat kesejahteraan nelayan sangat dipengaruhioleh hasil tangkapannya. Jika hasil tangkapan ikannya banyak, maka pendapatan mereka juga baik, begitu pula sebaliknya

Identifikasi Masalah pada penelitian ini adalah berapa besar pendapatan nelayan tradisional yang ada di Kecamatan Langsa Baro. Adapun tujuan dari penelitian ini adalah untuk mengetahui pendapatan nelayan tradisional nelayan yang ada diKecamatan Langsa Baro.

\section{Hipotesis}

Pendapatan nelayan di

Kecamatan Langsa Baro Kota Langsa rendah.

\section{Metode Penelitian}

Penelitian ini dilakukan dengan mengunakan metode survey di Kecamatan Langsa Baro. Penentuan desa sampel dilakukan secara sengaja (Purposive Sampling Dengan pertimbangan bahwa Kecamatan Langsa Baro merupakan salah satu daerah yang sebagian besar penduduknya berprofesi sebagai nelayan.). Pengambilan nelayan sampel dilakukan dengan mengunakan metode Simple Random Sampling Objek dalam penelitian ini hanya dibatasi pada pendapatan para nelayan tradisional yang menggunakan sampan/perahu dengan mesin motor tempel dan menggunakan alat tangkap yang sederhana seperti pancing, jala/jaring. Ruang lingkup dalam penelitian ini hanya pada pendapatan nelayan tradisional yang ada di Kecamatan Langsa Baro. Waktu peneltian dilakukan pada bulan November sampai Desember 2017. Untuk menghitunga pendapatan nelayan digunakan rumus (Soekartawi, 2002:57) :

$$
\begin{aligned}
& \pi=\text { TR }- \text { TC } \\
& \text { TR = TQ } \times \text { P } \\
& \text { TC = FC } \times \text { VC } \\
& \text { Keterangan : } \\
& \pi=\text { Pendapatan Bersih } \\
& \text { TR = Total Revenue } \\
& \text { TQ = Total Produksi/tangkapan } \\
& \text { TC = Total Cost } \\
& \text { FC = Fix Cost } \\
& \text { VC = Variable Cost } \\
& \text { P = Harga jual }
\end{aligned}
$$

\section{HASIL DAN PEMBAHASAN}

\section{Karakteristik Nelayan Tradisional}

Karakteristik nelayan dalam penelitian ini meliputi umur, pendidikan, dan pengalaman dalam berusaha nelayan dan besar tanggungan keluarga.Rini (2005:26), "pengertian karakteristik individu adalah bagian dari pribadi dan melekat pada diri seseorang.Karakteristik ini mendasari tingkah laku seseorang dalam situasi kerja maupun situasi yang lainnya". Karakteristik akan mempengaruhi nelayan dalam mengelola hasil tangkapan. Nelayan dalam menjalankan usahanya memiliki fungsi ganda yaitu disamping sebagai penjual juga sebagai buruh nelayan (juru nelayan).Karakteristik nelayan sampel di Kecamatan Langsa Baro dilihat pada tabel 1 Berikut ini.

Tabel 1. Rata - rata Karakteristik Nelayan di Kecamatan Langsa Baro, 2018

\begin{tabular}{|c|c|r|c|c|c|}
\hline \multirow{2}{*}{ No } & Desa & Umur & Pendidikan & Tanggunga & Pengalaman \\
\cline { 3 - 6 } & & (Tahun) & (Tahun) & (Orang) & (Tahun) \\
\hline 1 & Desa Alue Dua & 51,73 & 10,17 & 3,39 & 13,40 \\
\hline
\end{tabular}




\begin{tabular}{|c|l|r|r|r|c|}
\hline 2 & Desa Birem & 43,30 & 10,80 & 3,90 & 16,50 \\
\hline 3 & Desa Timbang & 40,00 & 12,00 & 3,00 & 15,00 \\
\hline \multirow{2}{*}{ Rata- Rata } & 43,07 & 10,03 & 3,00 & 15,38 \\
\hline
\end{tabular}

Sumber ; Data Primer, 2018

Tabel 1 di atas menjelaskan bahwa umur rata-rata nelayan adalah 43.07 tahun, umur tersebut umur yang produktif dalam menjalankan kegiatan sebagai nelayan. Tingkat pendidikan rata-rata adalah 10.03 tahun (SMP) dengan demikian tingkat pendidikan nelayan masih rendah. Semakin tinggi pendidikan nelayan maka kemampuannya dalam menerima inovasi dan perkembangan teknologi lebih cepat. Begitu pula sebaliknya semakin rendah pendidikan seorang nelayan maka akan menjadi hambatan dalam menerima inovasi dan perkembangan

\section{Penggunaan Tenaga Kerja Nelayan Tradisional}

Penggunaan tenaga kerja pada kegiatan nelayan yang dilakukan oleh nelayan itu sendiri, jika seorang nelayan membawa tenaga kerja maka setiap kegiatan dilakukan bersama. Untuk setiap fase

Tabel 2. Rata-Rata Penggunaan Tenaga Kerja Nelayan perbulan Kecamatan Langsa Baro, 2017

\begin{tabular}{|l|l|c|}
\hline No & \multicolumn{1}{|c|}{ Desa } & $\begin{array}{c}\text { Tenaga Kerja } \\
(\mathrm{HKP} / \mathrm{B} / \mathrm{n})\end{array}$ \\
\hline 1 & Alue Dua & 25 \\
2 & Birem Puntong & 48,3 \\
3 & Timbang Langsa & 24 \\
\hline \multicolumn{1}{|c|}{ Rata -rata } & 33,10 \\
\hline
\end{tabular}

Sumber : Data primer (diolah), 2018

Tabel 2 di atas dapat dilihat bahwa rata-rata pengunaan tenaga kerja nelayan sampel di Kecamatan Langsa Baro yaitu sebesar 33,10 HKP/Bulan. Pada desa Birem Puntong dengan jumlah nelayan 10 orang tenaga keerja yang teknologi dalam kegiatan nelayan. Rata-rata jumlah tanggungan nelayan adalah 3 orang merupakan tanggungan keluarga yang kecil, sehingga nelayan dapat dikatakan masih mampu membiayai keluarganya dan kegiatan melautnya. Rata-rata pengalaman nelayan 15.38 tahun. Merupakan pengalaman yang cukup lama, sehingga semakin lama pengalaman seorang nelayan maka dapat dikatakan cukup mahir dalam menjalankan usaha sebagai nelayan, sehingga mampu meningktkan pendapatan nelayan.

kegiatan, seluruhnya dikonversikan ke dalam Hari Kerja Pria (HKP). Rata-rata penggunaan tenaga kerja nelayan sampel di Kecamatan Langsa Baro dilihat pada tabel berikut digunakan sebanyak 48,3 HKP/Bln, hal ini disebabkan karena nelayan di desa Birem Puntong banyak yang melaut di saat malam hari sehingga memerlukan penggunaan tenaga kerja. 
Biaya Produksi Nelayan Tradisional

Rata-rata penggunaan biaya produksi nelayan (per/bln) pada nelayan sampel di
Kecamatan Langsa Baro dapat dilihat pada tabel berikut ini

Tabel.3 Rata-Rata Biaya Produksi Nelayan di Kecamatan Langsa Baro, 2017

\begin{tabular}{|c|l|c|c|c|}
\hline \multirow{2}{*}{ No } & \multicolumn{1}{|c|}{ Desa } & \multicolumn{2}{|c|}{ Biaya (Rp/Tahun) } & \multirow{2}{*}{ Biaya Produksi } \\
\cline { 3 - 4 } 1 & Alur Dua & 168.976 & 2.224 .944 & 2.393 .922 \\
2 & Birem Puntong & 280.879 & 1.330 .500 & 3.529 .983 \\
\hline \multicolumn{2}{|c|}{ Rata-Rata } & 162.606 & 2.622 .897 & 2.782 .054 \\
\hline
\end{tabular}

Sumber : Data Primer, 2018 (diolah)

Dari tabel 3 di atas dapat dilihat rata-rata biayaproduksi Nelayan di Kecamatan Langsa Baro yaitu sebesar Rp. 2.782.054/bulan. Rata-rata penggunaan biaya produksi tertinggi berada di desa Birem Puntong sebesar Rp.3.529.983/bulan, sedangkan biaya produksi terendah berada di

\section{Jumlah Hasil Tangkapan (Produksi) Nelayan Tradisonal}

Desa Timbang Langsa sebesar Rp.2.289.139/bulan. Hal ini disebabkan karena desa Birem Puntong lebih banyak menggunakan tenaga kerja, sehingga lebih banyak biaya produksi yang dikeluarka untuk memberi upah pada tenaga kerja tersebut

Tabel 4 Rata-Rata Produksi Nelayan Sampel di Kecamatan Langsa Baro, 2017

\begin{tabular}{|c|l|c|}
\hline No & \multicolumn{1}{|c|}{ Desa } & Produksi (Kg/Bulan) \\
\hline 1 & Alur Dua & 216 \\
\hline 2 & Birem Puntong & 165 \\
\hline 3 & Timbang Langsa & $\mathbf{1 8 0}$ \\
\hline
\end{tabular}

Sumber : Lampiran 5

Tabel 4 dapat dilihat bahwa ratarata produksi nelayan berupa ikan tongkol dan ikan regak di Kecamatan Langsa Baro yaitu sebanyak $180 \mathrm{~kg} /$ bulan. Rata-rata produksi ikan tongkol dan ikan regak tertinggi berada di Desa Birem Puntong yaitu sebesar $216 \mathrm{~kg} / \mathrm{bulan}$ dan produksi ikan tongkol dan ikan regak terkecil berada di Desa Alue Dua sebanyak $161 \mathrm{~kg} / \mathrm{bulan}$. Hasil produksi di desa Birem Puntong lebih banyak, hal ini disebabkan karena ada beberapa nelayan yang menggunakan tenaga kerja sehingga tingkat pendapatan nelayan yang menggunakan tenaga kerja dengan yang tidak menggunakan tenaga kerja sangat berbeda. 


\section{Nilai Produksi (Pendapatan Kotor) Nelayan tradisional}

Nilai produksi (pendapatan kotor) adalah total perkalian produksi dan harga produksi yang diterima nelayan dari usahanya. Besarnya nilai produksi sangat ditentukan oleh harga yang berlaku saat nelayan menjual hasil tangkapannya. Pada saat penelitian ini dilakukan harga ikan tongkol dan ikan regakdi Kecamatan Langsa Baro adalah Rp. 20.000,- perkilogram. Rata-rata nilai produksi nelayan di Kecamatan Langsa baro dapat dilihat pada tabel 5.5 berikut ini.

Tabel 5.5 Rata-Rata Nilai Produksi Nelayan KecamatanLangsa Baro, 2017

\begin{tabular}{|c|l|c|c|c|}
\hline No & \multicolumn{1}{|c|}{ Desa } & $\begin{array}{c}\text { Produksi } \\
(\mathrm{Kg} / \mathrm{bulan})\end{array}$ & $\begin{array}{c}\text { Harga } \\
(\mathrm{Rp} / \mathrm{Kg})\end{array}$ & $\begin{array}{c}\text { Nilai } \\
\text { Produksi } \\
(\mathrm{Rp} / \mathrm{bulan})\end{array}$ \\
\hline 1 & Alue Dua & 161 & 20.899 & 3.350 .176 \\
\hline 2 & Birem Puntong & 216 & 19.500 & 4.233 .600 \\
\hline 3 & Timbang Langsa & 165 & 20.000 & 3.300 .000 \\
\hline \multicolumn{2}{|l|}{ Rata - rata } & 180 & 20.379 & 3.641 .000 \\
\hline
\end{tabular}

Sumber : Data primer, 2018 (diolah)

Tabel 5 di atas dapat dilihat bahwa rata-rata nilai produksi nelayan di Kecamatan Langsa Baro yaitu sebesar Rp.3.641.000/bulan.Rata-rata nilai produksi tertinggi berada di Desa Birem Puntongyaitu sebesar Rp.4.233.600/bulan dan nilai produksi terkecil berada di Desa Timbang Langsasebesar Rp.3.300.000/bulan. Hal ini disebabkan karena perbedaan tingkat produksi ikan tongkol dan ikan regak yang didapat lebih tinggi di desa Birem Puntong.

\section{Pendapatan Bersih Nelayan tradisional}

Pendapatan bersih sangat dipengaruhi oleh besarnya nilai produksi dan besarnya biaya produksi usahatani karet.
Pendapatan bersih yaitu selisih antara nilai produksi dengan total biaya produksi. Rata-rata pendapatan bersih nelayan sampel di Kecamatan Langsa Baro dapat dilihat pada tabel 6 berikut ini 
Tabel 6 Rata-Rata Pendapatan Bersih Nelayan di Kecamatan LangsaBaro, 2017

\begin{tabular}{|c|l|c|c|c|}
\hline No & \multicolumn{1}{|c|}{ Desa } & $\begin{array}{c}\text { Nilai Produksi } \\
\text { (Rp/bulan) }\end{array}$ & $\begin{array}{c}\text { Biaya } \\
\text { Produksi } \\
\text { (Rp/Bulan) }\end{array}$ & $\begin{array}{c}\text { Pendapatan Bersih } \\
\text { (Rp/Bulan) }\end{array}$ \\
\hline 1 & Alue Dua & 3.350 .176 & 2.393 .922 & 986.800 \\
\hline 2 & Birem Puntong & 4.233 .600 & 3.529 .983 & 703.617 \\
\hline 3 & Timbang Langsa & 3.300 .000 & 2.289 .139 & 1.101 .861 \\
\hline \multicolumn{2}{|c|}{ Rata-Rata } & 3.641 .000 & 2.782 .054 & 862.084 \\
\hline
\end{tabular}

Sumber :Data Primer, 2018 (diolah)

Tabel 6 di atas dapat dilihat bahwa rata-rata pendapatan bersih nelayan sampel di Kecamatan Langsa Baro yaitu sebesar Rp.862.084/Bulan.Rata-rata pendapatan bersih tertinggi berada di Desa Timbang Langsa yaitu sebesar Rp.1.101.861/Bulan. Sedangkan pendapatan bersih terkecil berada di Desa Birem Puntong sebesar Rp.703.617/Bulan. Pendapatan bersih nelayan tradisional masih berada dalam kategori yang sangat rendah karena jika dibandingkan dengan tingkat pendapatan sesuai UMP (Upah Minimum Provinsi) Rp.2.800.000/Bln, hal ini yang menyebabkan para nelayan tradisional tidak sejahtera atau miskin. Selain itu tingkat pendapatan yang rendah juga dikarenakan pembayaran upah tenaga kerja.

\section{DAFTAR PUSTAKA}

Abu, ahmadi, 2007. Psikologi Sosial. Jakarta : RinekaCipta

Alam, S. 2006, Ekonomi, Jakarta : ESIS.

Asri. 2000. Analisis faktor - faktor yang mempengaruhi produktivitas perikanan laut. Tesis Universitas Andalas, Padang

BPS(Badan Pusat Statistik), kota langsa, 2015

Dinas Pangan, Pertanian, Kelautan, dan perikanan, Kota Langsa, 2016

Imron, masyuri. 2003. "Kemiskinan dalam Masyarakat Nelayan" dalam jurnal masyarakat dan budaya. PMBLIPI.

Kusnadi, 2003.Akar Kemiskinan Nelayan. LKis.Yogyakarta.

Nazir, Moh. 2005. Metode Penelitian. Cetakan ke V Ghalia Indonesia, Jakarta

Rini, H. 2005. Psikologi Perkembanagan . UT. Jakarta

Salman, 1995.Kemiskinan Struktural dan Polarisasi Sosial Pada Masyarakat

Nelayan. Ujung Pandang.

Sastrawidjaja, dkk 2002. Nelayan Nusantara, Pusat Pengolahan Produk

SosialEkonomi Kelautan dan Perikanan. Jakarta.

Soekartawi.1999.Agribisnis Teori dan Aplikasinya.Jakarta : $\quad$ Raja GrafindoPersada

Sujarno.2008. Analisis Faktor- Faktor yang Mempengaruhi Trend Nelayan diKabupaten Langkat.Tessis.Sekolah Pascasarjana USU. Medan.

Suratiyah,K. 2009. Ilmu Usahatani. Jakarta : Penebar Swadaya 
Sumarsono, Sonny. 2003. Ekonomi Manajemen Sumber Daya Manusia
danKetenagakerjaan.Yogyakarta

:Graha Ilmu 